\title{
Aging Exacerbates Depressive-like Behavior in Mice in Response to Activation of the Peripheral Innate Immune System
}

\author{
Jonathan P Godbout', Maïté Moreau', Jacques Lestage ${ }^{2}$, Jing Chen ${ }^{3,4}$, Nathan L Sparkman ${ }^{3,4}$, \\ Jason O' Connor ${ }^{3,4}$, Nathalie Castanon ${ }^{2}$, Keith W Kelley ${ }^{3,4,5}$, Robert Dantzer,4,5 and Rodney W Johnson*,3,4 \\ 'Department of Molecular Virology, Immunology and Medical Genetics, Institute for Behavioral Medicine, The Ohio State University, Columbus, \\ $\mathrm{OH}$, USA; ${ }^{2}$ Integrative Neurobiology, INRA-CNRS-University of Bordeaux 2, Bordeaux cedex, France; ${ }^{3}$ Integrative Immunology and Behavior \\ Program, University of Illinois, Urbana, IL, USA; ${ }^{4}$ Department of Animal Sciences, University of Illinois, Urbana, IL, USA and ${ }^{5}$ Department of \\ Pathology, University of Illinois, Urbana, IL, USA
}

\begin{abstract}
Exposure to peripheral infections may be permissive to cognitive and behavioral complications in the elderly. We have reported that peripheral stimulation of the innate immune system with lipopolysaccharide (LPS) causes an exaggerated neuroinflammatory response and prolonged sickness behavior in aged BALB/c mice. Because LPS also causes depressive behavior, the purpose of this study was to determine whether aging is associated with an exacerbated depressive-like response. We confirmed that LPS (0.33 mg/kg intraperitoneal) induced a protracted sickness response in aged mice with reductions in locomotor and feeding activities 24 and $48 \mathrm{~h}$ postinjection, when young adults had fully recovered. When submitted to the forced swim test $24 \mathrm{~h}$ post-LPS, both young adult and aged mice exhibited an increased duration of immobility. However, when submitted to either the forced swim test or the tail suspension test $72 \mathrm{~h}$ post-LPS, an increased duration of immobility was evident only in aged mice. This prolonged depressive-like behavior in aged LPStreated mice was associated with a more pronounced induction of peripheral and brain indoleamine 2,3-dioxygenase and a markedly higher turnover rate of brain serotonin (as measured by the ratio of 5-hydroxy-indoleacetic acid over 5-hydroxyt-tryptamine) compared to young adult mice at 24 post-LPS injection. These results provide the first evidence that age-associated reactivity of the brain cytokine system could play a pathophysiological role in the increased prevalence of depression observed in the elderly.

Neuropsychopharmacology (2008) 33, 234I-235I; doi: I0.1038/sj.npp. I 301649; published online 12 December 2007
\end{abstract}

Keywords: aging; behavior; cytokines; lipopolysaccharide; serotonin; depression

\section{INTRODUCTION}

Mounting evidence indicates that there is a causative relationship between inflammation and depression (Raison et al, 2006; Schiepers et al, 2005). The prevalence of depression is higher in chronically infected patients (Maes et al, 2001; Pollmacher et al, 2002), in patients with inflammatory disease (eg coronary heart disease or rheumatoid arthritis) (Glaser and Kiecolt-Glaser, 2005), and in cancer patients undergoing interleukin (IL)-2 and/or interferon- $\alpha$ (IFN $\alpha$ ) immunotherapy (Capuron et al, 2001) than in the general population. Moreover, proinflammatory cytokines including IL- 6 and IL- $1 \beta$ were elevated in the plasma or cerebrospinal fluid of depressed patients (Anisman et al, 1999; Dentino et al, 1999; Levine et al, 1999;

\footnotetext{
*Correspondence: Dr RW Johnson, 4 Animal Sciences Laboratory, 1207 W Gregory Drive, University of Illinois at Urbana-Champaign, Urbana, IL 61801, USA, Tel: + I 217 333-2118, Fax: + I $217333-$ 8286, E-mail: rwjohn@uiuc.edu

Received 20 September 2007; revised 30 October 2007; accepted 6 November 2007
}

Sluzewska et al, 1995; Thomas et al, 2005) and these heightened levels of cytokines were associated with the severity of depression. This relationship between cytokines and depression is particularly relevant to an older population that has a high incidence of behavioral and cognitive complications concomitant with proinflammatory conditions (Dentino et al, 1999; Glaser et al, 2003; Kiecolt-Glaser et al, 2003; Mulsant and Ganguli, 1999; Penninx et al, 1999, 2003).

In animal models, situations that promote brain proinflammatory cytokine production (eg IL-1 $\beta$, IL-6, or TNF $\alpha$ ) such as systemic lipopolysaccharide (LPS) challenge (Frenois et al, 2007), chronic infection with Bacilli CalmetteGuerin (BCG; Moreau et al, 2005), stroke (Craft and DeVries, 2006), and psychological stress (Chourbaji et al, 2006), resulted in depressive-like behavior. In regard to aging, we recently demonstrated that both peripheral and central stimulation of the innate immune system with LPS caused an exaggerated inflammatory cytokine response in the brain of aged mice (Godbout et al, 2005; Huang et al, 2007). Therefore, excessive exposure to inflammatory cytokines in the brain of aged may be permissive to the onset of long-lasting depressive-like deficits. 
Serotonin (5-hydroxytryptamine or 5-HT) plays a pivotal role in the regulation of mood (Mattson et al, 2004). Reductions in 5-HT availability or alterations in serotonergic transmission in the brain, including decreased 5-HT levels (Lesch, 2001), increased 5-HT transporters (Stockmeier, 2003), and genetic polymorphisms in the 5-HT transporter promoter (Caspi et al, 2003) have been associated with depressive symptoms in humans. Moreover, several classes of antidepressants including selective serotonin reuptake inhibitors and monoamine oxidase inhibitors are used in the treatment of depression because they can enhance 5-HT availability and augment 5-HT neurotransmission through a myriad of purported mechanisms including increased 5-HT sensitivity, increased expression of 5-HT receptors, decreased 5-HT reuptake, and decreased 5-HT metabolism (Millan, 2006). Although it is generally accepted that 5-HT-mediated processes are fundamental in depressive etiology, a consensus regarding the specific 5-HT receptor subtypes and 5-HT transporter alterations has not been reached (Millan, 2006).

Proinflammatory cytokines can directly or indirectly alter 5-HT metabolism, which could be an important biochemical connection between inflammation and depression. For instance, peripheral injection of LPS or recombinant cytokines (IL-1 or IL-6) increased brain levels of 5-HT and its main metabolite, 5-hydroxyindoleacetic acid (5-HIAA), in rodents (Dunn, 1992; Wang and Dunn, 1998, 1999; Zhang et al, 2001). Moreover, recent evidence showed that inflammation can disrupt 5-HT metabolism by altering the metabolism of tryptophan (TRP), the rate-limiting amino acid in 5-HT synthesis (Capuron et al, 2003, 2002). Proinflammatory cytokines including IFN $\gamma$ and tumor necrosis factor- $\alpha$ (TNF $\alpha)$ enhanced TRP catabolism through the activation of indoleamine 2,3-dioxygenase (IDO; Capuron and Dantzer, 2003; Wichers and Maes, 2004). This ubiquitous enzyme is expressed in many cell types including perivascular macrophages, astrocytes, and microglia of the CNS (Guillemin et al, 2005). In mice, BCG infection caused a persistent activation of peripheral and cerebral IDO, resulting in decreased TRP levels (Moreau et al, 2005).

In addition to the impact of IDO on serotonergic neurotransmission, active IDO increases several TRPderived neuroactive metabolites including kynurenine (KYN) and quinolinic acid (Capuron and Dantzer, 2003). These neuroactive metabolites can modulate glutamate receptor activity (Behan et al, 1999; Chiarugi et al, 2001; Okuda et al, 1998). In rodents, systemic immune activation and ischemic brain injury was associated with increased IDO-dependent catabolism of TRP, where elevated levels of brain KYN and quinolinic acid were detected (Lestage et al, 2002; Saito et al, 1993a,b). Moreover, a recent study demonstrated that LPS-induced depressive-like behavior (ie increased immobility in the forced swim and tail suspension tests (TSTs)) was mediated by a pathway involving cytokine production and IDO-dependent catabolism of TRP into KYN (O'Connor et al, 2007). These results showed that adult mice pretreated with the IDO antagonist, 1-methyl-tryptophan, did not exhibit depressive-like behavior in response to LPS and that peripheral administration of $\mathrm{KYN}$, in nonimmune-stimulated mice, mimicked the depressive-like effects of LPS (O'Connor et al, 2007). Taken together, activation of inflammatory pathways may ultimately increase the risk for depression by impacting both brain serotonergic and glutamatergic neurotransmission.

Our experiments were carried out to test the hypothesis that hypersensitivity to immune activation in the aged causes long-lasting behavioral complications. We show that aged mice exhibit depressive-like behavior following recovery from LPS-induced sickness, even after the acute effects of LPS have been resolved. Furthermore, aging is associated with increased brain IDO activity and 5-HT turnover in response to LPS. These findings support our hypothesis that reactivity of the brain cytokine system in aged individuals might mediate the higher prevalence of mood disorders in this population.

\section{MATERIALS AND METHODS}

\section{Animals}

Young adult (3- to 6-month-old) and aged (20- to 24month-old) male BALB/c mice from our in-house specific pathogen-free colony were used. Mice were individually housed in polypropylene cages and maintained at $21^{\circ} \mathrm{C}$ under a reverse phase $12 \mathrm{~h}$ light/dark cycle with ad libitum access to water and rodent chow. At the end of each study, mice were examined postmortem for gross signs of disease (eg splenomeglia or tumors). Data from mice determined to be unhealthy were excluded (less than $5 \%$ of all experimental animals). All procedures were approved by the campus Institutional Animal Care and Use Committee.

\section{Behavior}

Locomotor activity and forced swimming were measured as previously described (Godbout et al, 2005; Porsolt, 2000). In brief, mice were handled 2 min each day for 7 days before experimentation to acclimate them to routine handling. Tests were conducted during the dark phase (between 0800 and 1700 hours) of the photoperiod under infrared lighting to facilitate video recording.

Locomotor activity. Mice were maintained in their home cage, which provided a floor area of $26 \times 20 \mathrm{~cm}$, and locomotor activity was video-recorded during $3 \mathrm{~min}$ tests. On the video records, cages were divided into six identical rectangles and a trained observer who was blind to experimental treatments determined the number of line crossings.

Forced swimming. The forced swim test (FST) was initiated by placing mice in a inescapable cylinder (diameter $16 \mathrm{~cm}$, height $30 \mathrm{~cm}$ ) containing $15 \mathrm{~cm}$ of water maintained at $25^{\circ} \mathrm{C}$ (Lira et al, 2003). Forced swimming was video-recorded for $5 \mathrm{~min}$. When placed into the cylinder, mice immediately started swimming and climbing along the walls in attempts to escape. Immobility occurred more or less rapidly and was defined as motionless floating in the water with minimum movements. The duration of swimming, climbing, and immobility was determined by a trained observer who was blind to the experimental treatments.

Tail suspension. The TST was initiated by securing mice by the tail using adhesive tape positioned about $2.5 \mathrm{~cm}$ from 
the tail tip. Mice were suspended individually for $10 \mathrm{~min}$ and the duration of immobility was determined using an automated TST apparatus (Mouse Tail Suspension Package, MED-TSS-MS, Med Associates Inc., St Albans, VT). The testing apparatus consisted of $32 \times 33 \times 33 \mathrm{~cm}$ box with an open front side to allow visual observation during the test. An $11 \mathrm{~cm}$ vertical aluminum hook was attached to a strain gauge and suspended from the top of the box to detect any movement by the test mouse. Mice were determined immobile when the force of the mouse's movements (measure in voltage) was below a preset threshold. The optimum threshold was determined during a preliminary study and corresponds only to the time in which mice were making no active movement. The following settings were used for this experiment: threshold $=3$, gain $=4$, and resolution $=10 \mathrm{~ms}$.

\section{Real-Time PCR}

Total RNA was isolated from brain using the Tri Reagent protocol (Sigma, St Louis, MO). RNA samples were subjected to a DNase I digestion procedure and then reverse transcribed to cDNA using an RT RETROscript kit (Ambion, Austin, TX). Quantitative real-time PCR was performed using the Applied Biosystems (Foster, CA) assay-on demand gene expression protocol as previously described (Godbout et al, 2005). In brief, cDNA was amplified by PCR where a target cDNA (IDO, Mm00492586_m1) and a reference cDNA (glyceraldehyde-3-phosphate dehydrogenase, Mm99999915_g1) were amplified simultaneously using an oligonucleotide probe with a $5^{\prime}$ fluorescent reporter dye (6-FAM) and a $3^{\prime}$ quencher dye (NFQ). Fluorescence was determined on an ABI PRISM 7700 sequence detection system (PerkinElmer, Forest City, CA). All samples used for qPCR were run in duplicate. Data were analyzed using the comparative threshold cycle $\left(C_{\mathrm{t}}\right)$ method and results are expressed as fold difference (Livak and Schmittgen, 2001).

\section{IDO Activity}

IDO activity was measured as previously described (Lestage et al, 2002). In brief, whole brains were homogenized in icecold $20 \mathrm{mM}$ phosphate buffered saline ( $\mathrm{pH} 7.0)$ containing protease inhibitors (Sigma). Clarified cell lysates were incubated under agitation with $50 \mathrm{mM}$ potassium phosphate buffer ( $\mathrm{pH}$ 6.5), $0.4 \mathrm{mM}$ TRP, $20 \mathrm{mM}$ ascorbic acid, $10 \mu \mathrm{M}$ methylene blue, and $100 \mu \mathrm{g} / \mathrm{ml}$ catalase for $3 \mathrm{~h}$ at $37^{\circ} \mathrm{C}$. The reactions were blocked by adding $30 \%$ trichloroacetic acid (TCA) and then incubated for $30 \mathrm{~min}$ at $50^{\circ} \mathrm{C}$ to covert $\mathrm{N}$ formyl-kynurenine to L-kynurenine (L-KYN). After centrifugation $\left(13000 \mathrm{~g}\right.$ for $10 \mathrm{~min}$ at $\left.4{ }^{\circ} \mathrm{C}\right)$ and ultrafiltration (cutoff, $10000 M_{\mathrm{r}}$ ) the amount of L-KYN produced from TRP was determined by reverse phase HPLC. Reaction product was injected into a $5 \mu \mathrm{m} \mathrm{C}_{18} \mathrm{RP}-\mathrm{HPLC}$ column (Lichrospher, Alltech) with a flow rate of $1 \mathrm{ml} / \mathrm{min}$ using a mobile phase of $0.1 \mathrm{M}$ ammonium acetate/acetic acid buffer and $5 \%$ acetonitrile $(\mathrm{pH} 4.65)$. KYN was detected by UV absorbency at $360 \mathrm{~nm}$ and concentration was determined comparison with known KYN standards. One unit of activity was defined as $1 \mathrm{nmol} \mathrm{KYN}$ per $\mathrm{h}$ per $\mathrm{mg}$ of protein at $37^{\circ} \mathrm{C}$. Protein was determined by the bicinchoninic acid method.

\section{5-HT and 5-HIAA Measurement}

5-HT and 5-HIAA were measured in whole-brain homogenates. In brief, brains were homogenized in $20 \mathrm{mM}$ phosphate buffered saline $(\mathrm{pH} 7.0)$ containing protease inhibitors (Sigma). After protein precipitation with TCA and centrifugation ( $13000 \mathrm{~g}$ for $15 \mathrm{~min}$ at $4^{\circ} \mathrm{C}$ ), $20 \mu \mathrm{l}$ supernatants were injected into an RP-HPLC system equipped with a Coulochem II electrochemical detector at flow rate of $1 \mathrm{ml} / \mathrm{min}$ (1400-1500 p.s.i.). 5-HT and 5-HIAA were separated on a $C_{18}$ RP-HPLC column using a mobile phase of $0.1 \mathrm{M}$ ammonium acetate $(\mathrm{pH} 4.65)$ containing $5 \%$ acetonitrile. 5-HT and 5-HIAA concentrations were determined in samples by comparison of the retention time and peak areas with known standards.

\section{Tryptophan and Kynurenine Measurement}

Tryptophan and KYN were measured as previously described (Moreau et al, 2005). For brain TRP, whole brains were homogenized in phosphate buffered saline $(\mathrm{pH}$ 7.0). Brain homogenates were precipitated with $2 \mathrm{mM}$ of TCA and clarified by centrifugation $(13000 \mathrm{~g}$ for $10 \mathrm{~min}$ at $4{ }^{\circ} \mathrm{C}$ ). Supernatants were analyzed by HPLC using the protocol for IDO activity (described above). Levels of TRP were detected by fluorescence detector at $285 \mathrm{~nm}$ excitation and $360 \mathrm{~nm}$ emission wavelengths and concentration was determined in comparison with known TRP standards. Plasma levels of TRP and KYN were measured using the same techniques in plasma samples taken 24 and $72 \mathrm{~h}$ postLPS. Plasma KYN to TRP was calculated by dividing KYN concentration $(\mathrm{nmol} / \mathrm{l})$ by TRP concentration ( $\mu \mathrm{mol} / \mathrm{l})$ (Wirleitner et al, 2003).

\section{Plasma IL-6 Measurement}

IL-6 was measured in the plasma as previously described (Godbout et al, 2004). In brief, mice were anesthetized by $\mathrm{CO}_{2}$ inhalation and blood was collected by cardiac puncture into EDTA-coated syringes. Samples were centrifuged ( $4000 \mathrm{~g}$ for $15 \mathrm{~min}$ at $4^{\circ} \mathrm{C}$ ) and plasma was collected and stored frozen $\left(-80^{\circ} \mathrm{C}\right)$. Plasma samples were assayed for IL6 using a customized ELISA that we have described in detail (Godbout et al, 2004). All plasma samples for ELISA were run in duplicate. Assays were sensitive to $8 \mathrm{pg} / \mathrm{ml}$ of IL-6, and inter- and intraassay coefficients of variation were less than $10 \%$.

\section{Experimental Protocols}

For all studies, young adult and aged mice were injected intraperitoneally (i.p.) with saline or Escherichia coli LPS (0.33 mg/kg; serotype 0127:B8, Sigma). This LPS dosage was used because it elicits a proinflammatory cytokine response in the brain resulting in mild transient sickness behavior in adult mice (Berg et al, 2004; Godbout et al, 2005). In the first study, locomotor activity, food intake, and body weight were measured $0,24,48$, and $72 \mathrm{~h}$ after injection of saline or LPS $(n=9)$. In separate but identical studies, depressivelike behavior was assessed either 24 or $72 \mathrm{~h}$ postinjection. After completion of behavioral testing, mice were killed by $\mathrm{CO}_{2}$ asphyxiation and brain samples were collected and 
assayed for IDO activity $(n=6)$. Plasma was also collected and stored frozen $\left(-80^{\circ} \mathrm{C}\right)$ until assaying. In a subsequent study, young adult and aged mice were injected i.p. with saline or LPS and 4 or $24 \mathrm{~h}$ later mice were killed, brains were removed and stored in an RNA preservative solution $\left(-80^{\circ} \mathrm{C}\right)$. Total RNA was later isolated from brain samples for real-time PCR $(n=6)$. In a final study, young adult and aged mice were injected i.p. with saline or LPS and $24 \mathrm{~h}$ later mice were killed and brains were removed, and stored frozen $\left(-80^{\circ} \mathrm{C}\right)$ until assaying for IDO activity, 5-HT, 5 -HIAA, and TRP $(n=6)$. Plasma was also collected and stored frozen $\left(-80^{\circ} \mathrm{C}\right)$ until assaying.

\section{Statistical Analysis}

All data were analyzed using Statistical Analysis Systems (SAS) general linear model procedures. Data were subjected to two- (age $\times$ treatment) or three-way (age $\times$ treatment $\times$ time) analysis of variance to determine significant main effects as well as interactions between main factors. When appropriate, differences between treatment means were evaluated by protected $t$-tests using the LSD procedure of SAS. All data are expressed as the treatment means \pm SEM.

\section{RESULTS}

\section{Aging Prolongs LPS-Induced Behavioral Deficits and Depressive-Like Behavior}

We had previously shown that peripheral stimulation of the innate immune system with LPS caused an exaggerated proinflammatory cytokine response in the brain of aged mice compared to young adult cohorts. In that study, behavioral symptoms of sickness were similar in young adult and aged mice shortly after injection of LPS, but the exaggerated proinflammatory response in the brain of aged mice substantially delayed recovery of normal behavioral activities (Godbout et al, 2005). To control for any confounding effect of lethargy on performance in the FST it was desirable to test animals at a time before and after complete recovery of normal activities. To ascertain when behavior of young adult and aged mice returned to baseline following peripheral LPS injection, locomotor activity, food intake, and body weight were measured before i.p. injection of LPS and 24, 48, and $72 \mathrm{~h}$ later (Figure 1). There was a significant main effect of Age $(P<0.001$, for each) and LPS $(P<0.001$, for each), and a significant Age $\times$ LPS interaction for locomotor activity (LA), food intake (FI), and body weight $(\mathrm{BW})(\mathrm{LA}: \mathrm{F}(3,35)=6.53, P<0.01$; FI: $\mathrm{F}(3,35)=$ 4.28, $P<0.05$; $\mathrm{BW}: \mathrm{F}(3,35), 14.9, P<0.001)$. These data are consistent with our previous work that showed older mice were more sensitive to the sickness-inducing effects of LPS (Godbout et al, 2005). Young adult mice returned to normal locomotor activity $48 \mathrm{~h}$ after LPS injection, but locomotor activity of aged mice was still markedly reduced $(P<0.01)$. By $72 \mathrm{~h}$, however, both age groups had returned to normal locomotor activity.

A similar pattern of delayed recovery of aged mice from LPS was apparent in food intake (Figure 1b). Similar to locomotor activity, food intake of adult and aged mice decreased immediately after LPS injection. Whereas young adults returned to control levels by $48 \mathrm{~h}$, aged mice did not resume eating until $72 \mathrm{~h}$ postinjection $(P<0.01)$. Finally, LPS reduced body weight of young adult and aged mice $24 \mathrm{~h}$ after injection but weight loss was more pronounced in aged mice $(P<0.001)$. Furthermore, while young adults injected with LPS returned to near preinjection body weight by $72 \mathrm{~h}$ $(P=0.09)$, aged mice did not $(P<0.001)$. Collectively, these findings indicate that aged mice had a delayed recovery to LPS-induced sickness behavior, which is consistent with our previous results (Godbout et al, 2005).

To determine if aging also influenced LPS-induced depressive-like behavior, young adult and aged mice were subjected to either the FST (Figure 2a and b) or the TST (Figure 2c). Depressive-like behavior was measured $24 \mathrm{~h}$ after peripheral LPS challenge when both young adult and aged mice exhibited overt signs of illness and at $72 \mathrm{~h}$ when both age groups had normal food intake and locomotor behavior (Figure 1). At $24 \mathrm{~h}$ the duration of immobility in the force swim test increased due to LPS $(\mathrm{F}(1,35)=28.3$, $P<0.001)$, but not Age $(P=0.35)$. Young adult and aged mice given LPS spent a similar amount of time immobile (Figure 2a). At $72 \mathrm{~h}$, however, only aged mice given LPS spent markedly more time immobile in the FST than mice from the other three treatment groups, as revealed by the significant Age $\times$ LPS interaction $(F(1,55)=12.25$, $P<0.001$; Figure 2b). There was no detectable difference in time spent swimming or climbing between young adult and aged saline controls.

To confirm these findings at $72 \mathrm{~h}$, a second group of mice were subjected to a TST $(n=6)$. Parallel with the results from the FST $72 \mathrm{~h}$ postinjection, aged mice receiving LPS spent more time immobile in the TST than young adults receiving LPS (LPS $\times$ Age interaction: $\mathrm{F}(1,23)=4.5$, $P<0.04$; Figure 2c). Taken together, these data indicate that both young adult and aged mice exhibit depressive likebehavior when their innate immune system is stimulated with LPS ( $24 \mathrm{~h}$; Figure $2 \mathrm{a}$ ), but only the aged mice continue to exhibit depressive-like behavior $72 \mathrm{~h}$ post-LPS injection (Figure $2 b$ and $c$ ).

\section{Increased Tryptophan Metabolism at the Periphery in Aged Mice in Response to Peripheral LPS}

As expected, LPS increased the KYN to TRP ratio in the plasma of young adult and aged mice $24 \mathrm{~h}$ posttreatment (LPS factor: $F(1,23)=26.0, P<0.01$; Figure 3). However, this effect was more pronounced in aged than in young adult mice (Age $\times$ LPS interaction: $\mathrm{F}(1,23)=9.60, P<0.05$ ). This increased peripheral metabolism of TRP was not associated with any significant decrease in plasma levels of TRP and was mostly due to variations in KYN concentrations. The effects of LPS on TRP metabolism were no longer observed $72 \mathrm{~h}$ post-LPS (data not shown).

\section{Increased IDO Expression and Activity in Brain of Aged Mice in Response to Peripheral LPS}

To begin to investigate why LPS-induced depressive-like behavior was extended in aged mice, brain IDO mRNA levels in young adult and aged mice after peripheral injection of LPS were determined (Figure 4). Brain IDO mRNA was undetectable in saline-treated mice. Brain 

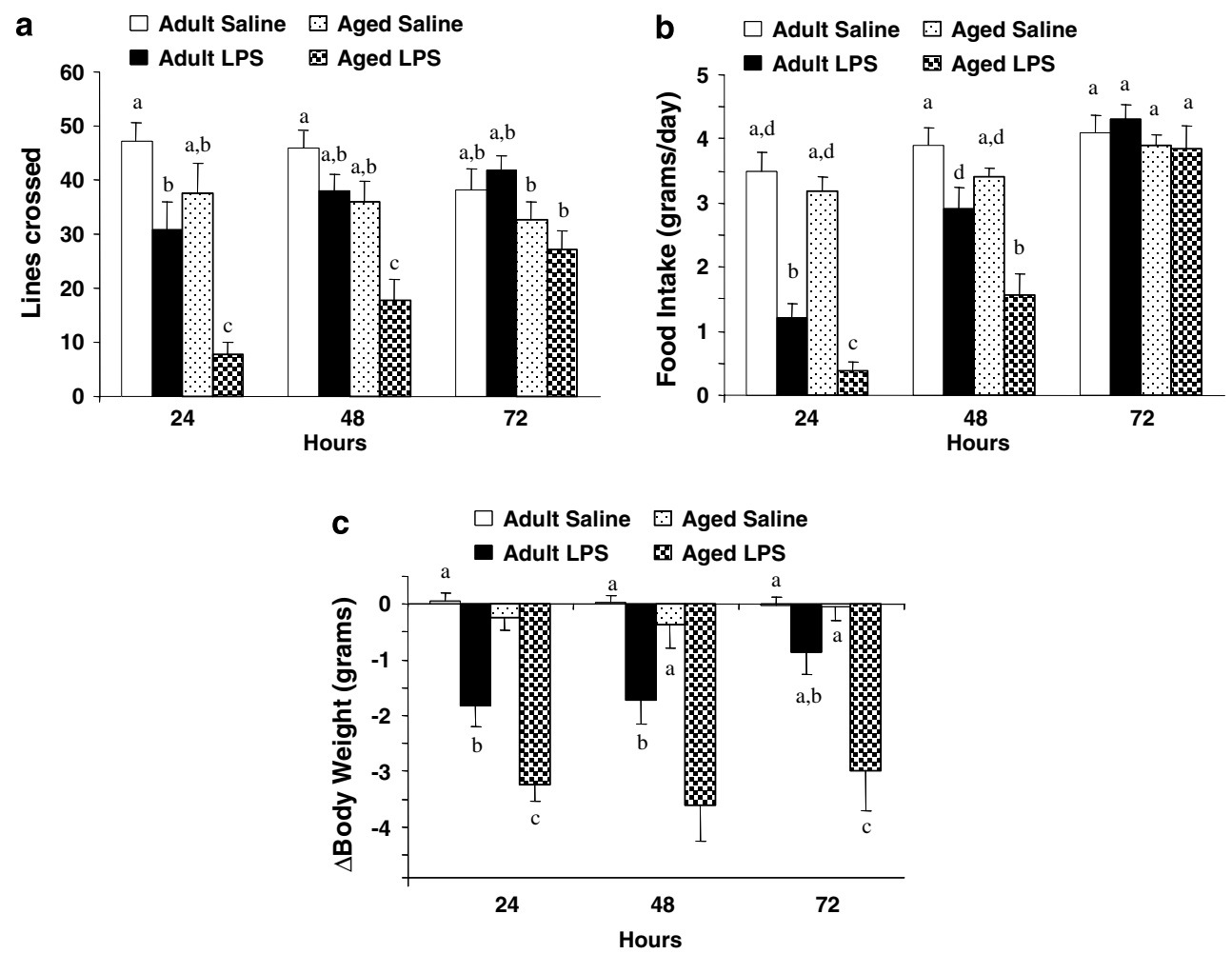

Figure I Aging prolonged lipopolysaccharide (LPS)-induced deficits in locomotor activity, food intake, and body weight. Young adult and aged mice were injected i.p. with either saline or LPS and (a) locomotor activity, (b) food intake, and (c) body weight were measured at 0, 24, 48, and 72 h after LPS. Bars represent the mean \pm SEM $(n=9)$. Means with different letters $(a, b, c$, or $d)$ are significantly different $(P<0.05)$ from each other. Bars denoted with the same letter (ie a) are equal to other bars denoted with the same letter (a) and are significantly different from bars denoted with different letters: (b), (c), or (d). Moreover, bars denoted with multiple letters (ie a, b) are significantly different only from bars denoted with a single different letter (c) and (d).

IDO mRNA levels were markedly elevated in LPS-treated mice $(\mathrm{F}(1,23)=8.91, P<0.01$; Figure $4 \mathrm{a}) 4 \mathrm{~h}$ after injection, irrespective of age. Analysis of brain IDO mRNA levels $24 \mathrm{~h}$ after injection revealed a significant Age $\times$ LPS interaction $(\mathrm{F}(1,23)=8.52, P<0.01)$. The steady-state level of brain IDO mRNA was 15 -fold higher in aged mice receiving LPS than in young adults receiving LPS. Thus, consistent with what was observed in the forced swim test, LPS increased steady-state levels of brain IDO mRNA in young adult and aged mice, but the levels remained elevated longer in aged mice than in young adults.

To determine if the increases in IDO mRNA after LPS were paralleled by increased IDO activity, brain homogenates from young adult and aged mice were assayed for IDO enzymatic activity. IDO activity was measured in the brain $24 \mathrm{~h}$ after LPS (Figure 5). Analysis of IDO activity revealed a significant main effect of Age $(F(1,23)=9.21$, $P<0.007)$ and an Age $\times$ LPS interaction $(\mathrm{F}(1,23)=6.5$, $P<0.01)$. Whereas IDO activity in young adult brain was not affected by LPS $24 \mathrm{~h}$ after injection, it was markedly increased in brains of aged mice $(P<0.01)$. Taken together, these results indicate that aging prolonged the increases in brain IDO mRNA expression and activity when the peripheral innate immune system was activated.

\section{Serotonin Turnover is Enhanced in Brain of Aged Mice in Response to Peripheral LPS}

To determine if the LPS-induced increase in IDO activity in aged brain was associated with increased 5-HT turnover, levels of 5-HT, 5-HIAA, and TRP were measured in brains of young adult and aged mice $24 \mathrm{~h}$ after injection of saline or LPS (Figure 6a). On the one hand, 5-HT concentration was higher in brains of aged mice compared to young adults $(\mathrm{F}(1,23)=7.30, \quad P<0.05), \quad$ and LPS increased 5-HT $(\mathrm{F}(1,23)=25, P<0.001)$ irrespective of age (Age $\times$ LPS, $P=0.4$ ). On the other hand, 5-HIAA concentration was higher in brains of aged mice compared to young adults $(\mathrm{F}(1,23)=148, \quad P<0.001)$, and LPS increased 5-HIAA in both age groups $(\mathrm{F}(1,23)=127, P<0.001)$, but the LPS-induced increase was much greater in aged brains than in brains of young adults (Age $\times$ LPS interaction: $\mathrm{F}(1,23)=19.46, P<0.001)$. TRP was higher in brains of aged mice compared to young adults $(\mathrm{F}(1,23)=38.78$, $P<0.001)$ and LPS increased brain TRP levels in aged mice but not young adults (Age $\times$ LPS: $F(1,23)=10.7, P<0.05$ ). The LPS-stimulated increase in brain 5-HT and metabolites is consistent with previous studies (Dunn, 1992). Moreover, these results indicated that LPS enhanced the synthesis and the degradation of 5-HT in the brain of aged mice. Therefore, 5-HT turnover rate was assessed by the ratio of 5-HIAA to 5-HT (Figure 6b). Analysis revealed a significant main effect of LPS $(\mathrm{F}(1,23)=32.31, P<0.001)$, Age $(\mathrm{F}(1,23)=65.85, P<0.001)$, and an Age $\times$ LPS interaction $(\mathrm{F}(1,23)=11.36, P<0.01)$. 5-HT turnover was higher in brains of aged mice than young adults, and activation of the peripheral innate immune system by LPS increased turnover in the brains of both young adult and aged mice, but the turnover was substantially accelerated in the aged brain. 

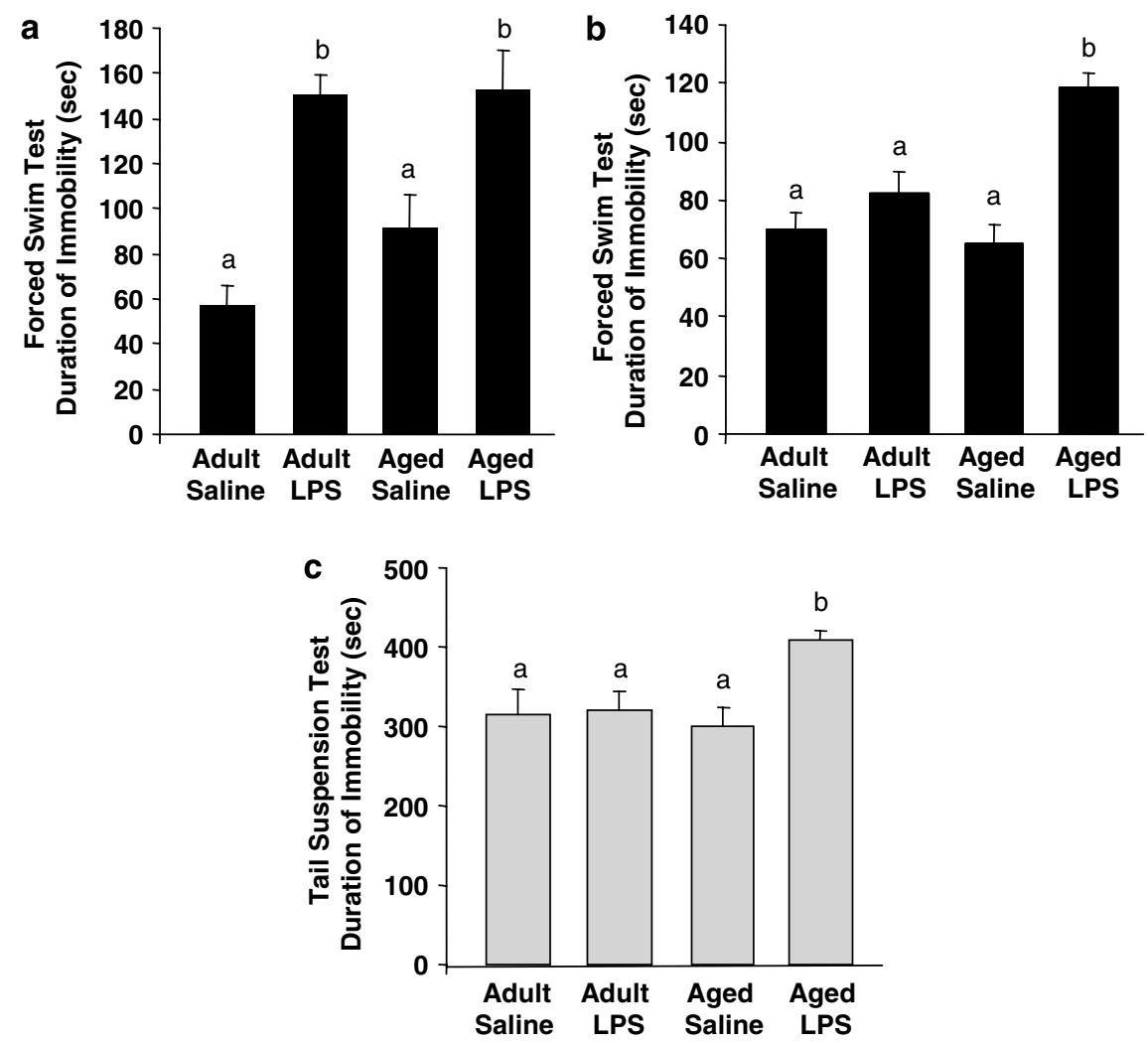

Figure 2 Depressive-like behavior was prolonged in aged mice $72 \mathrm{~h}$ following peripheral lipopolysaccharide (LPS) injection. Young adult and aged mice were injected i.p. with either saline or LPS and exposed to the forced swim test (a) 24 or (b) $72 \mathrm{~h}$ later. Bars represent the mean \pm SEM duration of immobility ( $n=8$ at $24 \mathrm{~h}$ and $n=14$ at $72 \mathrm{~h}$ ). In (a) and (b), means with different letters (a or b) are significantly different $(P<0.05)$ from each other. (c) Young adult and aged mice were injected i.p. with either saline or LPS and exposed to the tail suspension test $72 \mathrm{~h}$ later. Bars represent the mean \pm SEM duration of immobility $(n=6)$. Means with different letters $(a$ or $b)$ are significantly different $(P<0.05)$ from each other.

\begin{tabular}{|lllll|}
\hline & Adult Saline & \multicolumn{1}{c}{ Adult LPS } & Aged Saline & \multicolumn{1}{c|}{ Aged LPS } \\
$\mathbf{K Y N}(\mu \mathrm{mol} / \mathrm{L})$ & $0.65 \pm 0.06^{\mathrm{a}}$ & $0.83 \pm 0.11^{\mathrm{a}}$ & $0.64 \pm 0.07^{\mathrm{a}}$ & $1.39 \pm 0.10^{\mathrm{b}}$ \\
$\operatorname{TRP}(\mu \mathrm{mol} / \mathrm{L})$ & $72.2 \pm 6.1$ & $55.28 \pm 6.8$ & $64.4 \pm 3.52$ & $55.0 \pm 3.23$ \\
\hline
\end{tabular}

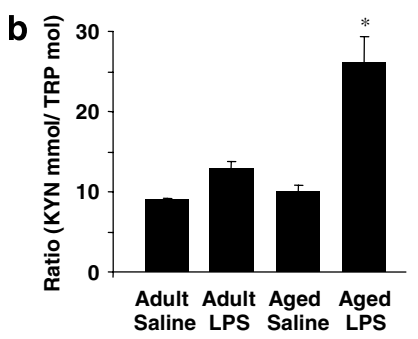

Figure 3 Increased tryptophan (TRP) metabolism in the plasma of aged mice in response to peripheral lipopolysaccharide (LPS) injection. (a) Young adult and aged mice were injected i.p. with either saline or LPS and TRP and kynurenine (KYN) were measured in plasma collected $24 \mathrm{~h}$ later. The table represents the mean \pm SEM $(n=6)$. Means with different letters (a or b) are significantly different $(P<0.05)$ from each other. (b) Metabolism of TRP as measured by the ratio of KYN to TRP. Bars represent mean \pm SEM $(n=6)$. Means with $(*)$ are significantly different $(P<0.05)$.

\section{Plasma IL-6 is Elevated in Aged Mice $24 \mathrm{~h}$ After Peripheral LPS}

We previously showed that IL-6 mRNA expression and protein production in the aged mouse brain remains significantly elevated $24 \mathrm{~h}$ after peripheral LPS injection (Godbout et al, 2005). Because increased plasma IL-6 was associated with increased depressive symptoms in older individuals, levels of plasma IL-6 were determined (Figure 7). Plasma IL-6 concentrations were dramatically higher in aged mice than in young adults $(\mathrm{F}(1,23)=5.94$, $P<0.02) 24 \mathrm{~h}$ after LPS injection. IL-6 was also assayed in plasma obtained $72 \mathrm{~h}$ after LPS injection, but no appreciable levels of IL-6 were detected (data not shown).

\section{DISCUSSION}

Because aging is associated with reactivity of the brain cytokine system to the effects of peripheral activation of the innate immune system (Barrientos et al, 2006; Godbout et al, 2005) and stimulation of the immune system can precipitate the occurrence of depression (Capuron et al, 2003, 2002; Glaser et al, 2003), we investigated whether aging was also associated with a higher sensitivity to the depressive-like behavioral effects of a peripheral stimulation of the innate immune system and the mechanisms responsible for this increased sensitivity. As anticipated, aged mice were more sensitive to the sickness-inducing effects of i.p. LPS challenge. In response to LPS, aged mice were anorexic longer, lost more body weight, and showed deficits in locomotor activity up to $48 \mathrm{~h}$ posttreatment. Both aged and young adult mice exhibited depressive-like 

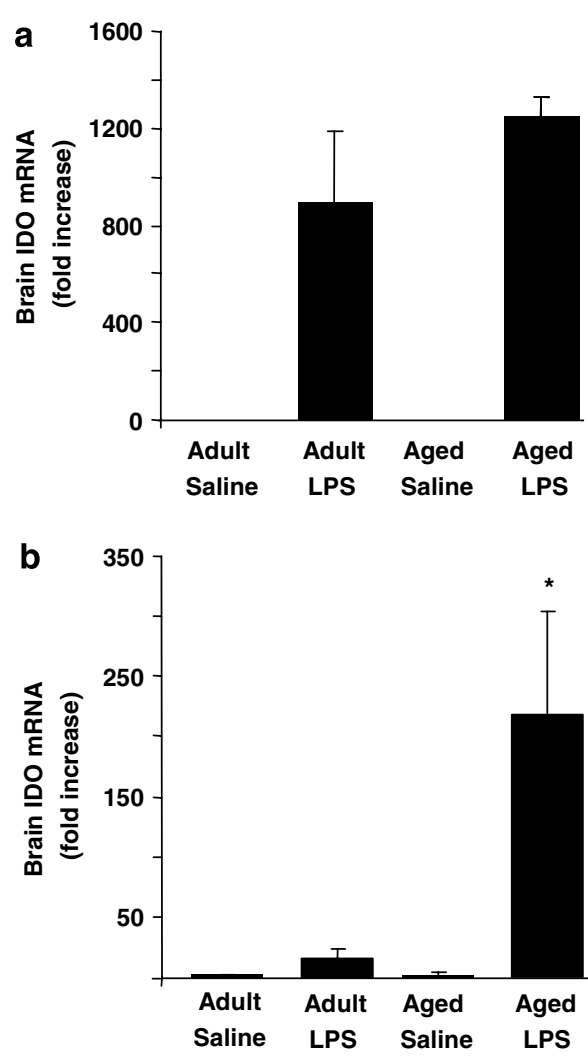

Figure 4 Increased indoleamine 2,3-dioxygenase (IDO) mRNA expression in brain of aged mice after peripheral lipopolysaccharide (LPS) injection. Young adult and aged mice were injected i.p. with either saline or LPS and IDO mRNA was measured by real-time RT-PCR in whole brain collected at (a) 4 or (b) $24 \mathrm{~h}$ later. Bars represent the mean $\pm \operatorname{SEM}(n=6)$. Means with $(*)$ are significantly different $(P<0.05)$.

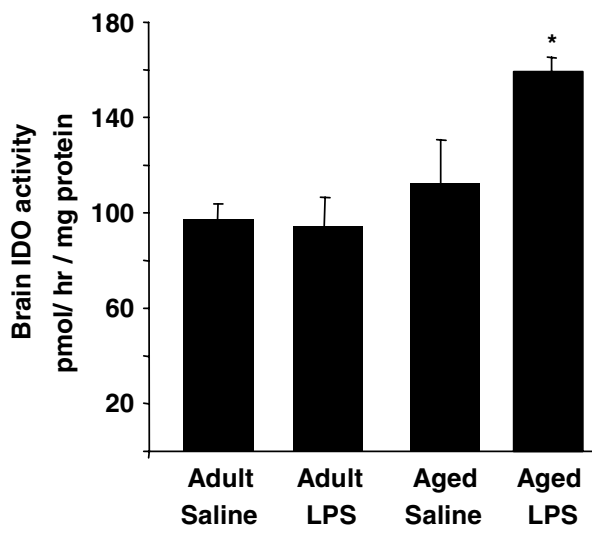

Figure 5 Elevated indoleamine 2,3-dioxygenase (IDO) enzymatic activity in brain of aged mice in response to peripheral lipopolysaccharide (LPS) injection. Young adult and aged mice were injected i.p. with either saline or LPS and IDO activity was measured in whole brain collected $24 \mathrm{~h}$ later. Bars represent the mean $\pm \operatorname{SEM}(n=6)$. Means with $(*)$ are significantly different $(P<0.05)$.

behavior $24 \mathrm{~h}$ after LPS challenge when clinical signs of illness were still evident. The most important finding, however, was that aged mice displayed longer durations of immobility in the FST and TST even after the sicknessinducing effects of LPS had dissipated. Aged mice also

\begin{tabular}{|lrrrl|}
\hline & Adult Saline & Adult LPS & Aged Saline & Aged LPS \\
5-HT (ng/protein) & $4.98 \pm 0.26^{\mathrm{a}}$ & $6.85 \pm 0.26^{\mathrm{b}}$ & $6.18 \pm 0.27^{\mathrm{b}}$ & $7.37 \pm 0.37^{\mathrm{c}}$ \\
5-HIAA (ng/protein) & $3.8 \pm 0.17^{\mathrm{a}}$ & $6.11 \pm 0.33^{\mathrm{b}}$ & $6.41 \pm 0.28^{\mathrm{b}}$ & $11.69 \pm 0.49^{\mathrm{c}}$ \\
TRP (mmol/m) & $0.28 \pm 0.01^{\mathrm{a}}$ & $0.26 \pm 0.01^{\mathrm{a}}$ & $0.32 \pm 0.02^{\mathrm{b}}$ & $0.38 \pm 0.01^{\mathrm{c}}$ \\
& & & & \\
\hline
\end{tabular}

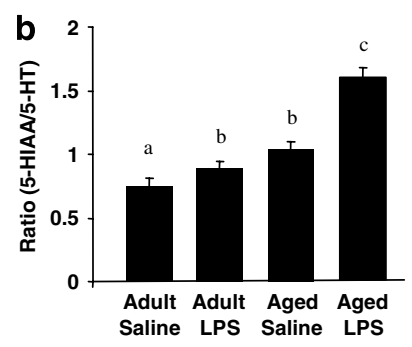

Figure 6 Increased serotonin (5-HT) turnover in the brain of aged mice in response to peripheral lipopolysaccharide (LPS) injection. (a) Young adult and aged mice were injected i.p. with either saline or LPS and 5-HT, 5-hydroxyindoleacetic acid (5-HIAA), and tryptophan (TRP) were measured in whole brain collected $24 \mathrm{~h}$ later. The table represents the mean $\pm \operatorname{SEM}(n=6)$. Means with different letters $(a, b$, or $c)$ are significantly different $(P<0.05)$ from each other. (b) Turnover rate of brain 5-HT as measured by the ratio of 5-HIAA to 5-HT. Bars represent mean \pm SEM $(n=6)$. Means with different letters $(a, b$, or $c)$ are significantly different $(P<0.05)$ from each other.

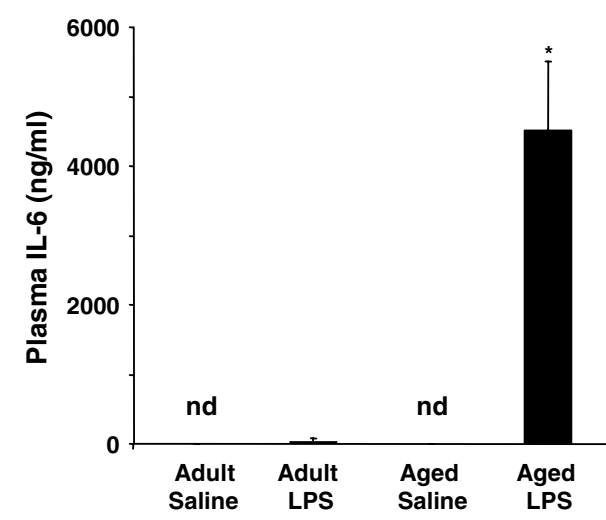

Figure 7 Elevated interleukin (IL)-6 in the plasma of aged mice in response to peripheral lipopolysaccharide (LPS) injection. Young adult and aged mice were injected i.p. with either saline or LPS and IL-6 was measured in plasma collected $24 \mathrm{~h}$ later. Bars represent the mean \pm SEM $(n=6)$. There was no detectable IL-6 (n.d.) in the plasma of saline-treated mice. Means with $(*)$ are significantly different $(P<0.05)$.

responded to LPS with a higher degradation of TRP at the periphery, a higher increase in brain IDO expression and activity, and a higher increase in brain 5-HT turnover. These effects of LPS were associated with a higher proinflammatory status, as measured by circulating levels of IL-6.

Our results indicate that aged mice injected with LPS displayed an increased duration of immobility in both the FST and the TST after other behavioral signs of illness waned (ie $72 \mathrm{~h}$ ). This finding is consistent with our hypothesis that aging is associated with an increased risk of depression (Godbout and Johnson, 2006). It is important to note that adults exhibited similar depressive-like behavior at $24 \mathrm{~h}$ (Figure 2a). Thus, the effects of old age on LPS-induced depressive-like behavior appear to be 


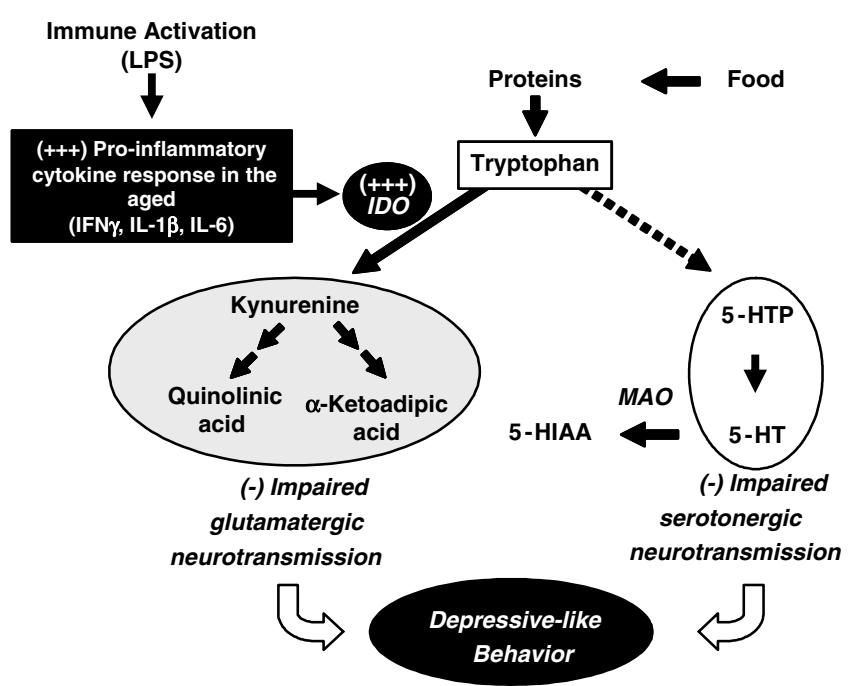

Figure 8 Proposed mechanism for the depressive-like effects of lipopolysaccharide (LPS) in the aged. In the aged, peripheral immune activation by LPS results in an exaggerated production of proinflammatory cytokines including interleukin (IL)- I $\beta$ (IL-I $\beta$ ), interferon- $\gamma$ (IFN $\gamma$ ), and IL-6 in the brain. These inflammatory cytokines induce the transcription and enzymatic activity of indoleamine 2,3-dioxygenase (IDO). IDO diverts tryptophan (TRP) from synthesis of 5-hydroxytryptophan (5-HTP) and 5 -hydroxytryptamine (5-HT) to the generation of TRP metabolites including kynurenine and quinolinic acid that act on glutamate receptors. This impacts both serotonergic and glutamatergic neurotransmission. The disruption in 5-HT metabolism may lead to a higher turnover of 5-HT with a reduction in 5-HT synthesis and increase in 5-HT degradation by monoamine oxidase (MAO) to 5-hydroxyindoleacetic acid (5-HIAA). The inflammatoryassociated imbalance between serotonergic and glutamatergic neurotransmission ultimately causes protracted depressive-like behavior in the aged.

related to rate of recovery, which is consistent with our previous findings on sickness behavior (Godbout et al, 2005).

A potential limitation, however, is that we determined depressive-like behavior using only the FST and the TST (Anisman and Matheson, 2005; Dunn et al, 2005). We used these tests because they are based upon the premise that depressive behaviors in mice are associated with resignation and helplessness (Porsolt, 2000). Both behavioral tests provide a strong motivating factor, water in the FST and hanging upside down in TST, for mice to actively attempt to escape. The behavioral results shown in Figure 2 indicate that aged mice treated with LPS are more prone to resign instead of trying to find an escape compared with all other treatments. Moreover, LPS-treated aged mice display longer durations of immobility (ie $72 \mathrm{~h}$; Figure $2 \mathrm{~b}$ and c) even after the sickness-inducing effects of LPS, reduced locomotor activity and food intake, had dissipated (Figure 1a and b). The distinction between sickness and depression is important because the behavioral symptoms of sickness may confound the results of the FST (Dunn and Swiergiel, 2005). Another potential confound of our behavioral testing is that aged mice treated with LPS may fatigue more rapidly. To control for this possible bias, time spent immobile in the FST was analyzed as the first $2.5 v s$ the second $2.5 \mathrm{~min}$. Aged mice injected with LPS spent more time immobile independent of the period of test (data not shown). These data are interpreted to indicate that aged mice treated with
LPS showed resignation as opposed to a general increase in lethargy and fatigue. Taken together, the FST and the TST are useful in determining depressive-like behavior, but we acknowledge that other measures of depressive-like behavior, such as decreased preference for a sweetened solution (anhedonia), could be used in the future to extend our initial findings.

Previous reports showed that immune activation, by peripheral LPS or BCG challenges, increased IDO activation in the brain and periphery of adult mice (Lestage et al, 2002; Moreau et al, 2005). In the present study, LPS injection increased IDO mRNA levels independent of age at $4 \mathrm{~h}$ postinjection, but the increase in IDO mRNA and activation persisted longer in the brain of aged mice (Figures 4 and 5). Because IDO is expressed in cells of the macrophage lineage, even in the brain (Guillemin et al, 2005; Heyes et al, 1997), a higher expression of IDO in aged mice following peripheral immune activation is consistent with the more reactive phenotype of macrophage-like cells and microglia in the aged brain (Frank et al, 2006; Godbout et al, 2005; Perry et al, 1993; Sheffield and Berman, 1998; Streit and Sparks, 1997).

Although there were significant Age $\times$ LPS increases in IDO activation and peripheral TRP metabolism at $24 \mathrm{~h}$ postinjection, these changes were not detected at $72 \mathrm{~h}$ when depressive behavior was still evident in aged mice. We have interpreted these data to indicate that increased IDO activation was a forerunner to depressive behavior. In support of this notion, LPS-treated young adult mice exhibited depressive-like behavior at $24 \mathrm{~h}$ (Figure 2a) even though there were no significant changes in either brain IDO mRNA levels or IDO enzymatic activity (Figure $4 \mathrm{~b}$ and Figure 5). The increased expression of IDO in the brain was rapid since LPS increased IDO mRNA within $4 \mathrm{~h}$, but basal levels of IDO returned by $24 \mathrm{~h}$ later in young adult mice (Figure 4). A similar event occurs in aged mice that still showed depressive-like behavior at $72 \mathrm{~h}$ post-LPS (Figure $2 \mathrm{~b}$ and c) despite IDO mRNA and enzymatic activities have normalized by that time. Therefore, the IDO activation response was extended in LPS-treated aged mice, but still paralleled the IDO induction and depressive behavior observed in adult mice. It is important to note that parallelism between behavioral changes and biochemical events can occur only when the corresponding techniques have the same sensitivity. In most cases, however, behavioral techniques are much more sensitive than biochemistry techniques especially when these techniques are applied to the whole brain. It is also important to mention that there was an overlap between the biochemistry and behavior in aged mice $24 \mathrm{~h}$ post-LPS challenge. LPS promoted depressive-like behavior in aged mice that was evident at $24 \mathrm{~h}$ (Figure 2a) and corresponded with the biochemical changes at the same time, including higher IDO activation and 5-HT turnover in brain (Figures 5 and 6) as well as higher plasma KYN and IL-6 levels (Figures 3 and 7). A limitation of this correlation, however, is that at 24 postinjection LPS-treated aged mice still showed symptoms associated with sickness (ie lethargy and decreased food intake; Figure 1a and b). Thus, because IDO activity was protracted in the aged brain, this in turn, extended depressive behavior, even to a point where depressive behavior could be differentiated from sickness behavior. 
Because IDO remained active in the aged brain $24 \mathrm{~h}$ postLPS injection, we expected TRP levels to be reduced at this time. This, however, was not the case. One explanation is the low-grade inflammation that is associated with aging (Godbout et al, 2005; Lee et al, 1999, 2000; Richwine et al, 2005; Ye and Johnson, 1999). Proinflammatory cytokines degrade proteins and increase the production of positive acute-phase proteins to the detriment of negative acutephase protein such as albumin, which should result in an increase in free TRP. The results on the metabolism of TRP at the periphery, as measured by circulating levels of KYN and TRP, follow in the same direction (Figure 3). In the present experiment the fact that TRP levels remained stable whereas KYN levels increased points to an increased bioavailability of TRP for IDO.

The incongruence between IDO activity and TRP and 5-HT levels may also be explained by the fact that TRP, 5-HT, and 5-HIAA were measured in whole-brain rather than in discrete brain structures. The effects of LPS on 5-HT and TRP metabolism are likely to vary across brain regions (eg prefrontal cortex, hippocampus, and brainstem). In this study, to determine both IDO activation and 5-HT metabolism in the same samples, whole-brain analyses were required. The whole-brain analysis is justified by the fact that the brain cytokine system is diffused rather than spatially localized in the brain since its cellular basis is represented by perivascular macrophages and parenchymal microglia (Perry et al, 2007). Future studies are necessary to determine the effects of LPS and aging on TRP and 5-HT metabolism, as well as 5-HT receptor subtypes, in discrete brain regions relevant to depression.

Increased brain 5-HT turnover in response to LPS has already been described (Dunn, 1992). The present study showed for the first time that these effects are more exaggerated in aged compared to young adult mice (Figure 6). Proinflammatory cytokines including IL-6 increased 5-HT, 5-HIAA, and TRP levels in the brain (Wang and Dunn, 1998). Although these changes were short-lived, it is possible that they are longer lasting in aged mice because proinflammatory cytokines induced by LPS remain significantly elevated in aged mice even $24 \mathrm{~h}$ after peripheral LPS injection. This was not only true at the periphery (Figure 7), but also in the brain since LPS-treated aged mice had higher levels of brain IL- $624 \mathrm{~h}$ post-LPS than young adults (Godbout et al, 2005). Thus, prolonged IL-6 exposure may increase 5-HT turnover (Dunn et al, 2005). Our findings support this notion because the ratio of 5HIAA to 5-HT was dramatically increased in aged mice $24 \mathrm{~h}$ post-LPS treatment (Figure 6b). Based on a marked increase in the ratio of 5-HIAA to 5-HT, we predict there will be reduction in 5-HT levels that will be both time and brain region dependent. Taken together, cytokine-associated disruption in 5-HT metabolism may not only underlie depressive behavior in our murine model, but also explain the inflammatory-related behavioral complications that occur in older individuals.

Whatever be the attractiveness of this hypothesis, the present experiments do not allow to determine whether the enhanced depressive-like behavior displayed by LPS-treated mice was due to the higher impact of LPS on serotonergic neurotransmission or to some other mechanism. Figure 8 summarizes the multiple pathways via peripheral immune stimuli may induce depressive-like behavior. Besides the direct effect of IDO activation on 5-HT synthesis from TRP, degradation of TRP by IDO results in the formation of neuroactive metabolites that act as antagonists (KYN) or agonists (quinolinic acid and 3-OH-kynurenine) of the NMDA receptor. These compounds can increase oxidative stress (Okuda et al, 1998) and overstimulate NMDA receptors (Behan et al, 1999; Chiarugi et al, 2001), both of which have potential deleterious effects on mental health (Wichers and Maes, 2004). The notion that these TRP metabolites play a pivotal role in LPS-induced depression behavior is corroborated by a recent study that used either minocycline, a tetracycline antibiotic with potent antiinflammatory activity, or 1-methyl-tryptophan, a specific competitive antagonist of IDO, to block LPS-induced activation of IDO. This report demonstrated that LPSinduced depressive-like behavior in adult mice was mediated by LPS-induced expression of proinflammatory cytokines and IDO-dependent catabolism of TRP into L-KYN (O'Connor et al, 2007).

In conclusion, the results of the present study show that the neurochemical and behavioral consequences of acute peripheral immune stimulation persist longer in aged mice than in young adults. These findings are important because a protracted neuroinflammatory response in the aged may promote depression. Although it still remains to be determined whether the same applies to chronic stimulation of the innate immune system, it is clear that pharmacological strategies aimed at decreasing neuroinflammation associated with infection could be important for improving recovery from sickness and reducing behavioral complications in the elderly.

\section{ACKNOWLEDGEMENTS}

This research was supported by the American Federation for Aging Research (AFAR) grant to JPG and the NIH grants (MH076786) to JPG, (AG029573) to KWK, (MH071349 and MH079829) to RD, and (AG16710 and MH069148) to RWJ.

\section{DISCLOSURE/CONFLICT OF INTEREST}

The authors declare that there are no actual or potential conflicts of interest. The authors affirm that there are no financial, personal, or other relationships with other people or organizations that have inappropriately influenced or biased their research.

\section{REFERENCES}

Anisman H, Matheson K (2005). Stress, depression, and anhedonia: caveats concerning animal models. Neurosci Biobehav Rev 29: $525-546$.

Anisman H, Ravindran AV, Griffiths J, Merali Z (1999). Endocrine and cytokine correlates of major depression and dysthymia with typical or atypical features. Mol Psychiatry 4: 182-188.

Barrientos RM, Higgins EA, Biedenkapp JC, Sprunger DB, WrightHardesty KJ, Watkins LR et al (2006). Peripheral infection and aging interact to impair hippocampal memory consolidation. Neurobiol Aging 27: 723-732.

Behan WM, McDonald M, Darlington LG, Stone TW (1999). Oxidative stress as a mechanism for quinolinic acid-induced 
hippocampal damage: protection by melatonin and deprenyl. $\mathrm{Br}$ J Pharmacol 128: 1754-1760.

Berg BM, Godbout JP, Kelley KW, Johnson RW (2004). Alphatocopherol attenuates lipopolysaccharide-induced sickness behavior in mice. Brain Behav Immun 18: 149-157.

Capuron L, Dantzer R (2003). Cytokines and depression: the need for a new paradigm. Brain Behav Immun 17(Suppl 1): S119-S124.

Capuron L, Neurauter G, Musselman DL, Lawson DH, Nemeroff CB, Fuchs D et al (2003). Interferon-alpha-induced changes in tryptophan metabolism: relationship to depression and paroxetine treatment. Biol Psychiatry 54: 906-914.

Capuron L, Ravaud A, Gualde N, Bosmans E, Dantzer R, Maes M et al (2001). Association between immune activation and early depressive symptoms in cancer patients treated with interleukin-2based therapy. Psychoneuroendocrinology 26: 797-808.

Capuron L, Ravaud A, Neveu PJ, Miller AH, Maes M, Dantzer R (2002). Association between decreased serum tryptophan concentrations and depressive symptoms in cancer patients undergoing cytokine therapy. Mol Psychiatry 7: 468-473.

Caspi A, Sugden K, Moffitt TE, Taylor A, Craig IW, Harrington H et al (2003). Influence of life stress on depression: moderation by a polymorphism in the 5-HTT gene. Science 301: 386-389.

Chiarugi A, Calvani M, Meli E, Traggiai E, Moroni F (2001). Synthesis and release of neurotoxic kynurenine metabolites by human monocyte-derived macrophages. J Neuroimmunol 120: 190-198.

Chourbaji S, Urani A, Inta I, Sanchis-Segura C, Brandwein C, Zink M et al (2006). IL-6 knockout mice exhibit resistance to stressinduced development of depression-like behaviors. Neurobiol Dis 23: $587-594$.

Craft TK, DeVries AC (2006). Role of IL-1 in poststroke depressive-like behavior in mice. Biol Psychiatry 60: 812-818.

Dentino AN, Pieper CF, Rao MK, Currie MS, Harris T, Blazer DG et al (1999). Association of interleukin-6 and other biologic variables with depression in older people living in the community. J Am Geriatr Soc 47: 6-11.

Dunn AJ (1992). Endotoxin-induced activation of cerebral catecholamine and serotonin metabolism: comparison with interleukin-1. J Pharmacol Exp Ther 261: 964-969.

Dunn AJ, Swiergiel AH (2005). Effects of interleukin-1 and endotoxin in the forced swim and tail suspension tests in mice. Pharmacol Biochem Behav 81: 688-693.

Dunn AJ, Swiergiel AH, de Beaurepaire R (2005). Cytokines as mediators of depression: what can we learn from animal studies? Neurosci Biobehav Rev 29: 891-909.

Frank MG, Barrientos RM, Biedenkapp JC, Rudy JW, Watkins LR, Maier SF (2006). mRNA up-regulation of MHC II and pivotal pro-inflammatory genes in normal brain aging. Neurobiol Aging 27: 717-722.

Frenois F, Moreau M, O'Connor J, Lawson M, Micon C, Lestage J et al (2007). Lipopolysaccharide induces delayed FosB/DeltaFosB immunostaining within the mouse extended amygdala, hippocampus and hypothalamus, that parallel the expression of depressive-like behavior. Psychoneuroendocrinology 32: 516-531.

Glaser R, Kiecolt-Glaser JK (2005). Stress-induced immune dysfunction: implications for health. Nat Rev Immunol 5: 243-251.

Glaser R, Robles TF, Sheridan J, Malarkey WB, Kiecolt-Glaser JK (2003). Mild depressive symptoms are associated with amplified and prolonged inflammatory responses after influenza virus vaccination in older adults. Arch Gen Psychiatry 60: 1009-1014

Godbout JP, Berg BM, Kelley KW, Johnson RW (2004). Alphatocopherol reduces lipopolysaccharide-induced peroxide radical formation and interleukin-6 secretion in primary murine microglia and in brain. J Neuroimmunol 149: 101-109.
Godbout JP, Chen J, Abraham J, Richwine AF, Berg BM, Kelley KW et al (2005). Exaggerated neuroinflammation and sickness behavior in aged mice following activation of the peripheral innate immune system. FASEB J 19: 1329-1331.

Godbout JP, Johnson RW (2006). Age and neuroinflammation: a lifetime of psychoneuroimmune consequences. Neurol Clin 24: 521-538.

Guillemin GJ, Smythe G, Takikawa O, Brew BJ (2005). Expression of indoleamine 2,3-dioxygenase and production of quinolinic acid by human microglia, astrocytes, and neurons. Glia 49: 15-23.

Heyes MP, Saito K, Chen CY, Proescholdt MG, Nowak Jr TS, Li J et al (1997). Species heterogeneity between gerbils and rats: quinolinate production by microglia and astrocytes and accumulations in response to ischemic brain injury and systemic immune activation. J Neurochem 69: 1519-1529.

Huang Y, Henry CJ, Dantzer R, Johnson RW, Godbout JP (2007). Exaggerated sickness behavior and brain proinflammatory cytokine expression in aged mice in response to intracerebroventricular lipopolysaccharide. Neurobiol Aging, e-pub ahead of print.

Kiecolt-Glaser JK, Preacher KJ, MacCallum RC, Atkinson C, Malarkey WB, Glaser R (2003). Chronic stress and age-related increases in the proinflammatory cytokine IL-6. Proc Natl Acad Sci USA 100: 9090-9095.

Lee CK, Klopp RG, Weindruch R, Prolla TA (1999). Gene expression profile of aging and its retardation by caloric restriction. Science 285: 1390-1393.

Lee CK, Weindruch R, Prolla TA (2000). Gene-expression profile of the ageing brain in mice. Nat Genet 25: 294-297.

Lesch KP (2001). Serotonergic gene expression and depression: implications for developing novel antidepressants. J Affect Disord 62: 57-76.

Lestage J, Verrier D, Palin K, Dantzer R (2002). The enzyme indoleamine 2,3-dioxygenase is induced in the mouse brain in response to peripheral administration of lipopolysaccharide and superantigen. Brain Behav Immun 16: 596-601.

Levine J, Barak Y, Chengappa KN, Rapoport A, Rebey M, Barak V (1999). Cerebrospinal cytokine levels in patients with acute depression. Neuropsychobiology 40: 171-176.

Lira A, Zhou M, Castanon N, Ansorge MS, Gordon JA, Francis JH et al (2003). Altered depression-related behaviors and functional changes in the dorsal raphe nucleus of serotonin transporterdeficient mice. Biol Psychiatry 54: 960-971.

Livak KJ, Schmittgen TD (2001). Analysis of relative gene expression data using real-time quantitative PCR and the 2(-Delta Delta C(T)) method. Methods 25: 402-408.

Maes M, Bonaccorso S, Marino V, Puzella A, Pasquini M, Biondi M et al (2001). Treatment with interferon-alpha (IFN alpha) of hepatitis $\mathrm{C}$ patients induces lower serum dipeptidyl peptidase IV activity, which is related to IFN alpha-induced depressive and anxiety symptoms and immune activation. Mol Psychiatry 6: 475-480.

Mattson MP, Maudsley S, Martin B (2004). BDNF and 5-HT: a dynamic duo in age-related neuronal plasticity and neurodegenerative disorders. Trends Neurosci 27: 589-594.

Millan MJ (2006). Multi-target strategies for the improved treatment of depressive states: conceptual foundations and neuronal substrates, drug discovery and therapeutic application. Pharmacol Ther 110: 135-370.

Moreau M, Lestage J, Verrier D, Mormede C, Kelley KW, Dantzer R et al (2005). Bacille Calmette-Guerin inoculation induces chronic activation of peripheral and brain indoleamine 2,3-dioxygenase in mice. $J$ Infect Dis 192: 537-544.

Mulsant BH, Ganguli M (1999). Epidemiology and diagnosis of depression in late life. J Clin Psychiatry 60(Suppl 20): 9-15.

O'Connor J, Lawson M, Andre C, Moreau M, Lestage J, Castanon N et al (2007). Lipopolysaccharide-induced depressive-like behavior 
is mediated by indoleamine 2,3 dioxygenase activation in mice. Mol Psychiatry (in press).

Okuda S, Nishiyama N, Saito H, Katsuki H (1998). 3-Hydroxykynurenine, an endogenous oxidative stress generator, causes neuronal cell death with apoptotic features and region selectivity. J Neurochem 70: 299-307.

Penninx BW, Geerlings SW, Deeg DJ, van Eijk JT, van Tilburg W, Beekman AT (1999). Minor and major depression and the risk of death in older persons. Arch Gen Psychiatry 56: 889-895.

Penninx BW, Kritchevsky SB, Yaffe K, Newman AB, Simonsick $\mathrm{EM}$, Rubin $\mathrm{S}$ et al (2003). Inflammatory markers and depressed mood in older persons: results from the Health, Aging and Body Composition study. Biol Psychiatry 54: 566-572.

Perry VH, Cunningham C, Holmes C (2007). Systemic infections and inflammation affect chronic neurodegeneration. Nat Rev Immunol 7: 161-167.

Perry VH, Matyszak MK, Fearn S (1993). Altered antigen expression of microglia in the aged rodent CNS. Glia 7: 60-67.

Pollmacher T, Haack M, Schuld A, Reichenberg A, Yirmiya R (2002). Low levels of circulating inflammatory cytokines - do they affect human brain functions? Brain Behav Immun 16: $525-532$.

Porsolt RD (2000). Animal models of depression: utility for transgenic research. Rev Neurosci 11: 53-58.

Raison CL, Capuron L, Miller AH (2006). Cytokines sing the blues: inflammation and the pathogenesis of depression. Trends Immunol 27: 24-31.

Richwine AF, Godbout JP, Berg BM, Chen J, Escobar J, Millard DK et al (2005). Improved psychomotor performance in aged mice fed diet high in antioxidants is associated with reduced ex vivo brain interleukin-6 production. Brain Behav Immun 19: 512-520.

Saito K, Crowley JS, Markey SP, Heyes MP (1993a). A mechanism for increased quinolinic acid formation following acute systemic immune stimulation. J Biol Chem 268: 15496-15503.

Saito K, Nowak Jr TS, Suyama K, Quearry BJ, Saito M, Crowley JS et al (1993b). Kynurenine pathway enzymes in brain: responses to ischemic brain injury $v s$ systemic immune activation. J Neurochem 61: 2061-2070.
Schiepers OJ, Wichers MC, Maes M (2005). Cytokines and major depression. Prog Neuropsychopharmacol Biol Psychiatry 29: 201-217.

Sheffield LG, Berman NE (1998). Microglial expression of MHC class II increases in normal aging of nonhuman primates. Neurobiol Aging 19: 47-55.

Sluzewska A, Rybakowski JK, Laciak M, Mackiewicz A, Sobieska M, Wiktorowicz K (1995). Interleukin-6 serum levels in depressed patients before and after treatment with fluoxetine. Ann NY Acad Sci 762: 474-476.

Stockmeier CA (2003). Involvement of serotonin in depression: evidence from postmortem and imaging studies of serotonin receptors and the serotonin transporter. J Psychiatr Res 37: 357-373.

Streit WJ, Sparks DL (1997). Activation of microglia in the brains of humans with heart disease and hypercholesterolemic rabbits. J Mol Med 75: 130-138.

Thomas AJ, Davis S, Morris C, Jackson E, Harrison R, O'Brien JT (2005). Increase in interleukin-1beta in late-life depression. Am J Psychiatry 162: 175-177.

Wang J, Dunn AJ (1998). Mouse interleukin-6 stimulates the HPA axis and increases brain tryptophan and serotonin metabolism. Neurochem Int 33: 143-154.

Wang J, Dunn AJ (1999). The role of interleukin-6 in the activation of the hypothalamo-pituitary-adrenocortical axis and brain indoleamines by endotoxin and interleukin-1 beta. Brain Res 815: 337-348.

Wichers MC, Maes M (2004). The role of indoleamine 2, 3-dioxygenase (IDO) in the pathophysiology of interferonalpha-induced depression. J Psychiatry Neurosci 29: 11-17.

Wirleitner B, Rudzite V, Neurauter G, Murr C, Kalnins U, Erglis A et al (2003). Immune activation and degradation of tryptophan in coronary heart disease. Eur J Clin Invest 33: 550-554.

Ye SM, Johnson RW (1999). Increased interleukin-6 expression by microglia from brain of aged mice. J Neuroimmunol 93: 139-148.

Zhang J, Terreni L, De Simoni MG, Dunn AJ (2001). Peripheral interleukin-6 administration increases extracellular concentrations of serotonin and the evoked release of serotonin in the rat striatum. Neurochem Int 38: 303-308. 